\title{
Evaluation of contact spermicidal potential of Lantana camara leaf extracts on human spermatozooa
}

\author{
Nitish Bhatia ${ }^{1}$, Kewal Singh ${ }^{1}$, Gaurav Shorey ${ }^{2}$, Gurjeet Singh $^{3}$, Ravi Dhawan $^{1}$ \\ ${ }^{1}$ Pharmacology Research Laboratory, Department of Pharmacology, Khalsa College of Pharmacy, Amritsar, Punjab, \\ India \\ ${ }^{2}$ Khalsa Diagnostic Laboratory, Khalsa College of Pharmacy, Amritsar, Punjab, India \\ ${ }^{3}$ Pharmaceutics Research Laboratory, Department of Pharmaceutics, Khalsa College of Pharmacy, Amritsar, Punjab, \\ India
}

Received: 05 September 2016

Accepted: 01 October 2016

\section{*Correspondence:}

Dr. Nitish Bhatia,

E-mail: nitishnitish_18@yahoo.com

Copyright: $\odot$ the author(s), publisher and licensee Medip Academy. This is an open-access article distributed under the terms of the Creative Commons Attribution Non-Commercial License, which permits unrestricted non-commercial use, distribution, and reproduction in any medium, provided the original work is properly cited.

\section{ABSTRACT}

Background: The Present study was designed to evaluate the spermicidal potential of various Lantana camara leaf extracts on healthy human spermatozoa.

Methods: Four different extracts viz. Petroleum ether, Chloroform, Methanol and Water were prepared and diluted to various concentrations. These were then treated with suitably diluted human semen samples. Various parameters like sperm motility, sperm viability, sperm count, hypoosmotic swelling, acrosomal status and function were noted.

Results: The results showed that methanolic and aqueous extracts possessed maximum spermicidal potential in terms of above mentioned sperm health and function parameters. Therefore, methanolic and aqueous extracts were further studied for In-vitro evaluation of pro-oxidant activity by detection of ROS generation using fluorescent probe detection method.

Conclusions: The results revealed that both methanolic and aqueous extracts of Lantana camara possessed prooxidant potential which could be attributed for its observed contact spermicidal activity.

Keywords: Free radicals, Lantana camara, Pro-oxidant, Spermicidal

\section{INTRODUCTION}

Rapid growth of population is the world's major problem. In order to get control on this rapid growth, various approaches have been developed $\&$ are being evolved to prevent unwanted pregnancies. These include physical and chemical approaches. ${ }^{1}$ Till now, none of the approaches can be considered as ideal. Use of contact spermicidal agents has found prominence as well as preference as an effective method of contraception due to their fast acting nature, negligible possibility of systemic side effects and an added advantage of possible use by women to prevent pregnancy. ${ }^{2}$ Although many types of spermicidal contraceptives are available, they are associated with side effects and hence are not easily accepted. $^{3}$

The chemical compounds affecting testicular function include different groups like steroidal and non-steroidal. But application of all of these compounds has been seriously questioned owing to various hazards as they were proved toxic or idiosyncratic on both the short as well as long term use in the reproductive organs. ${ }^{4}$ However, use of extracts of medicinal plants is commonly associated with low or negligible toxic effect on short term use on the reproductive organs. Moreover, long term use associated effects may still be under estimated. ${ }^{5}$ 
The choice of Lantana camara for present investigation is based on the cytotoxic nature of plant. Cytotoxicity of Vero cell line treated with various dilutions of $L$. camara's leaf extract for $24 \mathrm{~h}$ and $72 \mathrm{~h}$ has also been reported. ${ }^{6}$ Recently the cell culture method was used for the production of secondary metabolites of $L$. camara cells in suspension cultures and reported to possessed cytotoxic activity. ${ }^{7}$ The bioactivity of the cell-derived extract was demonstrated using cancerous HeLa cell lines. Specifically, the effect of this extract on HeLa cells was noticed from $36 \mathrm{~h}$ (at $100 \mu \mathrm{g} / \mathrm{mL}$ ) to $72 \mathrm{~h}$ (at 25 $\mu \mathrm{g} / \mathrm{mL})$ by employing the 3-(4,5-dimethylthiazol-2-yl)2,5-diphenyltetrazolium bromide (MTT) cytotoxicity assay. ${ }^{8}$ In addition, other researchers used the aqueous extract $(0.23 \%)$, obtained from callus cultures of $L$. camara (50 g dry mass), showing it had an apparent cytotoxic effect on HeLa cells with an IC50 value of $1,500 \mu \mathrm{g} / \mathrm{mL}$ in $36 \mathrm{~h}$. A dose-time dependent activity of the extract was established ${ }^{9}$. Furthermore, in different works, isolated compounds from L. camara especially lantadene $\mathrm{A}, \mathrm{B}$ and $\mathrm{C}$ were found to produce strong hepatotoxic response in rodents. ${ }^{10}$

Research has shown that ROS causes electron leakage from actively respiring spermatozoa, mediated by intracellular redox activities. The generation of ROS in spermatozoa may occur via two methods: (1) the nicotinamide adenine dinucleotide phosphate (NADP) oxidase system at the level of the sperm plasma membrane and/or (2) the nicotinamide adenine dinucleotide-dependent oxido-reductase reaction at the mitochondrial level. The latter mechanism appears to be the main source of ROS. Spermatozoa are rich in mitochondria because a constant supply of energy is required for their motility. ${ }^{11}$ Therefore, the presence of dysfunctional spermatozoa in the semen significantly elevates the production of ROS, which in turn affects its mitochondrial function and subsequently, sperm function such as motility. Although the cytotoxic nature of Lantana camara and many of its phytoconstituents is well documented, yet, to the best of our knowledge, no study has been documented regarding the spermicidal action of the plant extracts. ${ }^{12}$

Therefore the present study was designed to evaluate the possible spermicidal potential of Lantana camara leaf extract in human spermatozoa.

\section{METHODS}

\section{Crude drug}

Leaves of the plant Lantana camara, family were collected from Botanical garden of Khalsa College, Amritsar (Punjab). The plant material was identified and authenticated by Department of Botany, Khalsa College, Amritsar vide letter number 62012032014. A specimen voucher of the plant material has been submitted to the herbarium for reference purpose.

\section{Preparation of plant extracts}

The leaves of Lantana camara were dried and coarsely powdered using an electrical grinder. Various extracts of the powdered drug were prepared using different solvents in the increasing order of their polarity viz. Petroleum ether followed by chloroform followed by methanol and distilled water. The solvents present in the extracts were completely removed by solvent evaporation using a Rota Evaporator (IKA®, Model: RV10DS96). As all the extracts (Except Aqueous extract) may contain lipid soluble extractive, the extracts were centrifuged at 3000 rpm for $20 \mathrm{~min}$. the supernatant was frozen at $-20^{\circ} \mathrm{C}$ till further investigation. Different concentrations of various extracts were prepared using saline or Arachis oil. Four different extracts i.e. petroleum ether, chloroform, methanol and aqueous extract were used to evaluate their spermicidal activity at various concentrations. For control sample, sperm suspension was mixed with physiological saline (pH-7.5) in equal concentration. Highly non-polar petroleum ether extract and chloroform extract were diluted with arachis oil to prepare different concentrations.

\section{Phyto-chemical screening of plant extract}

The chemical tests for the screening and identification of phyto-constituents in the medicinal plants under study were carried out for all extracts as per the standard methods. Extracts were dissolved individually in $5 \mathrm{~mL}$ of respective solvents and filtered. The filtrates were used to test for the presence of various phyto-constituents. Various tests were conducted on each filtrate of the every extract. The main test conducted for the phytochemical screening was detection of alkaloids, detection of carbohydrates, detection of tannins, detection of flavonoids, detection of saponins, detection of steroids, detection of proteins.

\section{Preparation of sperm suspension}

The in vitro experiment was conducted on human sperm. The semen sample was collected from male healthy volunteers. Semen samples were collected in clean and dry beaker and routine semen analysis was done by various methods of estimation using Olympus microscope (Olympus Corporation Tokyo, Japan, Model - CX41RF) after liquefaction of semen at $37^{\circ} \mathrm{C}$.

\section{Test for spermicidal activity (Sperm mobility and $E_{50}$ )}

The spermicidal activity was determined using a modified version of the protocol originally described by which measures the minimum concentration of spermicidal agent required to completely immobilize/kill $100 \%$ sperm within 30 s. $^{6}$ The mixture was placed on clean glass slides. The slide was examined under Olympus microscope (Olympus Corporation Tokyo, Japan, Model - CX41RF) at 400X and mobility and motility of sperms was noted. 


\section{Sperm viability test}

Viability of sperm was examined by using EosinNigrosin technique ${ }^{13}$. In this method sperm suspension was mixed with different concentration of various extracts. Few drops of the resulting suspension were mixed with two drops of $(1 \% w / v)$ eosin solution. After few seconds, three drops of nigrosin solution $(10 \% \mathrm{w} / \mathrm{v})$ were added and mixed well. A smear was made by placing a drop of the mixture on clear glass slide. The smear was dried in air and examined under Olympus microscope (Olympus Corporation Tokyo, Japan, Model - CX41RF). Pink stained count as dead sperm and unstained sperm count as live.

\section{Hypo-osmotic swelling test}

Hypo-osmotic swelling solution was prepared by dissolving $0.735 \%$ of sodium citrate $(0.735 \mathrm{~g})$ and $1.351 \%$ fructose $(1.351 \mathrm{~g})$ in $100 \mathrm{ml}$ of distilled water ${ }^{14}$.

\section{Acrosomal status and functional test}

A clean glass slides was coated with gelatin solution and fixed with glutaraldehyde solution $(0.05 \% \mathrm{v} / \mathrm{v})$. On the day of experiment, semen samples were diluted with PBS-d-glucose. Various smears were prepared on the gelatin slide using $10 \mu \mathrm{L}$ of diluted semen samples. The slides were again incubated at $37^{\circ} \mathrm{C}$ for 2 hours. The enzymes (present in the semen) dissolved the gelatin and create holes in the slides. The holes created on each slide were counted and the percentage was noted. This method was done according to method of Gopalkrishnan ${ }^{15}$.

\section{Sperm count Test}

The number of live spermatozoa in the ejaculate was calculated from their concentration as per an already established method ${ }^{16}$. Semen sample was diluted in fixative solution. The composition of fixative solution was $50 \mathrm{~g}$ of sodium bicarbonate and $10 \mathrm{ml}$ of $35 \%(\mathrm{v} / \mathrm{v})$ formalin in $1 \mathrm{~L}$ of distilled water. Equal quantities of different concentrations of the extract solutions were added to fixative solution treated sperm samples. The resultant suspension was placed in neubauer hemocytometer. The sample was examined in all the four chambers of hemocytometer under Olympus microscope (Olympus Corporation Tokyo, Japan, Model - CX41RF). Each chamber contained 16 squares. This method was used to count the live and dead sperms.

\section{In-vitro Evaluation of Pro-oxidant Activity-Detection of ROS generation in human sperm}

The intracellular reactive oxygen species (ROS) level was detected by using the fluorescent probe DCFDA, as reported earlier ${ }^{17}$. DCFDA is a cell-permeable nonfluorescent probe that is de-esterified intra-cellularly and turns irreversibly into highly fluorescent 2', 7'dichlorofluorescein (DCF) upon oxidation. Fluorescence intensity is directly proportional to the amount of ROS. Human sperm cells were washed with Lock's buffer (154 $\mathrm{mM} \mathrm{NaCl}, 5.6 \mathrm{mM} \mathrm{KCl}, 3.6 \mathrm{mM}$, NaHCO3 $5.6 \mathrm{mM}$ Glucose, 5.0 mM HEPES), re-suspended in the same buffer and equilibrated with $10 \mathrm{mM}$ DCFDA for $1 \mathrm{~h}$ at $378 \mathrm{C}$. Thereafter, $10^{6}$ cells $/ 200 \mu \mathrm{l} /$ well were loaded in black 96-well micro plate and the DCF fluorescence was measured before and after the addition of spermicidal compounds at MEC (final concentration) in a fluorescence microplate reader (FLx800, Bio-Tek) using excitation and emission wavelengths of 485 and $530 \mathrm{~nm}$, respectively. FeSO4 (100 mM) was used as a positive control.

\section{RESULTS}

\section{Pharmacognostic Evaluation of Plant Extract}

Extracts were obtained in the form of suspension Different quantities of extracts i.e. $3.5 \mathrm{~g}$ petroleum ether extract, $2.8 \mathrm{~g}$ chloroform extract, $2.1 \mathrm{~g}$ ethanolic extract and $1.5 \mathrm{~g}$ aqueous extract were obtained from $55 \mathrm{~g}$ of the leaves. The extracts obtained were diluted by serial dilution method to prepare several concentrations (Table - 1).

Table 1: Phytochemical screening of plant extracts.

\begin{tabular}{|c|c|c|c|c|}
\hline Tests & $\begin{array}{l}\text { Petroleum } \\
\text { ether extract }\end{array}$ & $\begin{array}{l}\text { Chloroform } \\
\text { extract }\end{array}$ & $\begin{array}{l}\text { Methanol } \\
\text { extract }\end{array}$ & $\begin{array}{l}\text { Aqueous } \\
\text { extract }\end{array}$ \\
\hline $\begin{array}{l}\text { Alkaloids } \\
\text { Hager's reagent } \\
\text { Test sol. + saturated solution of picric acid. } \\
\text { Yellow ppt formed } \\
\text { Wagner's reagent } \\
\text { Test sol. + iodine solution + potassium iodide. } \\
\text { Brown ppt formed }\end{array}$ & -ve & $\begin{array}{l}\text { +ve } \\
\text { +ve }\end{array}$ & -ve & -ve \\
\hline $\begin{array}{l}\text { Saponins } \\
\text { Froth formation test } \\
2 \mathrm{ml} \text { solution in water }+ \text { shake well. } \\
\text { Foam is formed }\end{array}$ & $+v e$ & -ve & +ve & $+v e$ \\
\hline
\end{tabular}




\begin{tabular}{|c|c|c|c|c|}
\hline $\begin{array}{l}\text { Steriods } \\
\text { Salkowski test } \\
\text { Test sol. + few drops of conc. Sulphuric acid. } \\
\text { Red colour at lower layer }\end{array}$ & +ve & -ve & -ve & +ve \\
\hline $\begin{array}{l}\text { Flavonoids } \\
\text { Alkaline reagent test } \\
\text { Test sol. + few drops of } \mathrm{NaOH} \text { sol. } \\
\text { Yellow colour is formed turns to colourless on } \\
\text { addition of few drops of dilute acid } \\
\text { Zinc hydrochloride test } \\
\text { Test sol.+ zinc dust+ conc } \mathrm{HCl} \\
\text { Red colour after few minutes }\end{array}$ & -ve & -ve & +ve & +ve \\
\hline $\begin{array}{l}\text { Tannins } \\
\text { Ferric chloride test } \\
\text { Extract+ ferric chloride sol. } \\
\text { Blue colour or green colour } \\
\text { Gelatin test: } \\
\text { Test sol.+ } 1 \% \text { gelatin }+10 \% \mathrm{NaCl} \\
\text { Ppt formed }\end{array}$ & -ve & $+v e$ & $+\mathbf{v e}$ & +ve \\
\hline $\begin{array}{l}\text { Proteins } \\
\text { Warming test } \\
\text { Heat the test solution in water bath } \\
\text { Proteins get coagulated }\end{array}$ & $+v e$ & -ve & +ve & -ve \\
\hline $\begin{array}{l}\text { Anthraquinone glycosides } \\
\text { Borntrager's test } \\
\text { Boil the test sol.+1ml sulphuric acid for five } \\
\text { minutes+ filter the sol.+ shake with equal } \\
\text { volume of chloroform+ seprate the lower layer } \\
\text { of chloroform and shake with dilute ammonia } \\
\text { Rose pink to red colour is reduced } \\
\text { Hydroxy anthraquinones } \\
\text { Test sol.+ KOH solution } \\
\text { Red colour produced }\end{array}$ & +ve & -ve & -ve & -ve \\
\hline
\end{tabular}

Table 2: Sperm mobility test of various extract treated semen sample.

\begin{tabular}{|lllll|}
\hline $\begin{array}{l}\text { Concentration of } \\
\text { extract }\end{array}$ & $\begin{array}{l}\text { Percentage of sperm } \\
\text { Aqueous extract } \\
\text { (Mobility of } \\
\text { sperms } \pm \text { SEM) }\end{array}$ & $\begin{array}{l}\text { Methanol extract } \\
\text { (Mobility of } \\
\text { sperm } \pm \text { SEM) }\end{array}$ & $\begin{array}{l}\text { Chloroform extract } \\
\text { (Mobility of } \\
\text { sperms } \pm \text { SEM) }\end{array}$ & $\begin{array}{l}\text { Pet ether extract } \\
\text { (Mobility of } \\
\text { sperms } \pm \text { SEM) }\end{array}$ \\
\hline Control & $98 \pm 0.9$ & $97 \pm 0.8$ & $98 \pm 0.7$ & $98 \pm 0.7$ \\
\hline $100(\mu \mathrm{g} / \mathrm{ml})$ & $79 \pm 0.7$ & $88 \pm 0.7$ & $90 \pm 0.8$ & $92 \pm 0.6$ \\
\hline $200(\mu \mathrm{g} / \mathrm{ml})$ & $61 \pm 0.6$ & $80 \pm 0.7$ & $83 \pm 0.8$ & $87 \pm 0.7$ \\
\hline $300(\mu \mathrm{g} / \mathrm{ml})$ & $43 \pm 0.4$ & $51 \pm 0.6$ & $72 \pm 0.8$ & $81 \pm 0.8$ \\
\hline $400(\mu \mathrm{g} / \mathrm{ml})$ & $22 \pm 0.2$ & $30 \pm 0.4$ & $68 \pm 0.6$ & $77 \pm 0.8$ \\
\hline $500(\mu \mathrm{g} / \mathrm{ml})$ & $7 \pm 0.6$ & $10 \pm 0.3$ & $62 \pm 0.3$ & $72 \pm 0.8$ \\
\hline $600(\mu \mathrm{g} / \mathrm{ml})$ & $2 \pm 0.3$ & $7 \pm 0.6$ & $59 \pm 0.2$ & $65 \pm 0.6$ \\
\hline $700(\mu \mathrm{g} / \mathrm{ml})$ & 0 & $1 \pm 0.5$ & $56 \pm 0.1$ & $61 \pm 0.7$ \\
\hline $800(\mu \mathrm{g} / \mathrm{ml})$ & 0 & 0 & $56 \pm 0.7$ & $58 \pm 0.8$ \\
\hline $900(\mu \mathrm{g} / \mathrm{ml})$ & 0 & 0 & $52 \pm 0.7$ & $55 \pm 0.4$ \\
\hline $1000(\mu \mathrm{g} / \mathrm{ml})$ & 0 & 0 & $49 \pm 0.5$ & $51 \pm 0.5$ \\
\hline
\end{tabular}


Table 3: Sperm viability test (Eosin-Nigrosin staining) of various extract treated semen sample.

\begin{tabular}{|lllll|}
\hline $\begin{array}{l}\text { Concentration of } \\
\text { extract }\end{array}$ & $\begin{array}{l}\text { Percentage of stained (nonviable) sperms } \\
\text { Aqueous extract } \\
\text { (Stained sperms) }\end{array}$ & $\begin{array}{c}\text { Methanol extract } \\
\text { (Stained sperms) }\end{array}$ & $\begin{array}{c}\text { Chloroform extract } \\
\text { (Stained sperms) }\end{array}$ & $\begin{array}{c}\text { Pet ether extract } \\
\text { (Stained sperms) }\end{array}$ \\
\hline Control & 0 & 0 & 0 & 0 \\
\hline $100(\mu \mathrm{g} / \mathrm{ml})$ & 20 & 15 & 0 & 0 \\
\hline $200(\mu \mathrm{g} / \mathrm{ml})$ & 45 & 32 & 4 & 0 \\
\hline $300(\mu \mathrm{g} / \mathrm{ml})$ & 61 & 48 & 11 & 5 \\
\hline $400(\mu \mathrm{g} / \mathrm{ml})$ & 81 & 63 & 17 & 17 \\
\hline $500(\mu \mathrm{g} / \mathrm{ml})$ & 94 & 82 & 28 & 22 \\
\hline $600(\mu \mathrm{g} / \mathrm{ml})$ & 100 & 98 & 34 & 29 \\
\hline $700(\mu \mathrm{g} / \mathrm{ml})$ & 100 & 100 & 41 & 40 \\
\hline $800(\mu \mathrm{g} / \mathrm{ml})$ & 100 & 100 & 48 & 45 \\
\hline $900(\mu \mathrm{g} / \mathrm{ml})$ & 100 & 100 & 53 & 51 \\
\hline $1000(\mu \mathrm{g} / \mathrm{ml})$ & 100 & 100 & 64 & \\
\hline
\end{tabular}

Table 4: Hypo-osmotic swelling tests (Tail curling) of various extract treated semen sample.

\begin{tabular}{|lcccc|}
\hline $\begin{array}{l}\text { Concentration of } \\
\text { extract }\end{array}$ & $\begin{array}{c}\text { Percentage of tail curling } \\
\text { Aqueous extract } \\
\text { (Stained sperms) }\end{array}$ & $\begin{array}{c}\text { Methanol extract } \\
\text { (Stained sperms) }\end{array}$ & $\begin{array}{c}\text { Chloroform extract } \\
\text { (Stained sperms) }\end{array}$ & $\begin{array}{c}\text { Pet ether extract } \\
\text { (Stained sperms) }\end{array}$ \\
\hline Control & 99 & 99 & 98 & 98 \\
\hline $100(\mu \mathrm{g} / \mathrm{ml})$ & 89 & 91 & 96 & 95 \\
\hline $200(\mu \mathrm{g} / \mathrm{ml})$ & 71 & 76 & 92 & 87 \\
\hline $300(\mu \mathrm{g} / \mathrm{ml})$ & 58 & 59 & 85 & 83 \\
\hline $400(\mu \mathrm{g} / \mathrm{ml})$ & 45 & 49 & 81 & 79 \\
\hline $500(\mu \mathrm{g} / \mathrm{ml})$ & 32 & 36 & 77 & 74 \\
\hline $600(\mu \mathrm{g} / \mathrm{ml})$ & 18 & 23 & 71 & 69 \\
\hline $700(\mu \mathrm{g} / \mathrm{ml})$ & 8 & 11 & 65 & 54 \\
\hline $800(\mu \mathrm{g} / \mathrm{ml})$ & 0 & 3 & 59 & 51 \\
\hline $900(\mu \mathrm{g} / \mathrm{ml})$ & 0 & 0 & 53 & \\
\hline $1000(\mu \mathrm{g} / \mathrm{ml})$ & 0 & 0 & 46 & \\
\hline
\end{tabular}

Table 5: Acrosomal status and functional test of various extract treated semen sample.

\begin{tabular}{|lllll|}
\hline $\begin{array}{l}\text { Concentration of } \\
\text { extract }\end{array}$ & $\begin{array}{l}\text { Percentage of Holes } \\
\begin{array}{l}\text { Aqueous extract } \\
\text { (Stained sperms) }\end{array}\end{array}$ & $\begin{array}{c}\text { Methanol extract } \\
\text { (Stained sperms) }\end{array}$ & $\begin{array}{c}\text { Chloroform extract } \\
\text { (Stained sperms) }\end{array}$ & $\begin{array}{c}\text { Pet ether extract } \\
\text { (Stained sperms) }\end{array}$ \\
\hline Control & 100 & 100 & 100 & 100 \\
\hline $100(\mu \mathrm{g} / \mathrm{ml})$ & 92 & 95 & 100 & 100 \\
\hline $200(\mu \mathrm{g} / \mathrm{ml})$ & 83 & 85 & 100 & 100 \\
\hline $300(\mu \mathrm{g} / \mathrm{ml})$ & 65 & 72 & 100 & 96 \\
\hline $400(\mu \mathrm{g} / \mathrm{ml})$ & 54 & 61 & 94 & 88 \\
\hline $500(\mu \mathrm{g} / \mathrm{ml})$ & 38 & 45 & 82 & 76 \\
\hline $600(\mu \mathrm{g} / \mathrm{ml})$ & 20 & 27 & 77 & 55 \\
\hline $700(\mu \mathrm{g} / \mathrm{ml})$ & 0 & 12 & 64 & 48 \\
\hline $800(\mu \mathrm{g} / \mathrm{ml})$ & 0 & 0 & 55 & 39 \\
\hline $900(\mu \mathrm{g} / \mathrm{ml})$ & 0 & 0 & 47 & 33 \\
\hline $1000(\mu \mathrm{g} / \mathrm{ml})$ & 0 & 0 & 42 & \\
\hline
\end{tabular}


Table 6: Sperm count of various extract treated semen sample.

\begin{tabular}{|c|c|c|c|c|}
\hline \multirow[b]{2}{*}{$\begin{array}{l}\text { Concentration of } \\
\text { extract }\end{array}$} & \multicolumn{4}{|c|}{ Average number of live sperms (millions) } \\
\hline & $\begin{array}{l}\text { Aqueous extract } \\
\text { (Stained sperms) }\end{array}$ & $\begin{array}{l}\text { Methanol extract } \\
\text { (Stained sperms) }\end{array}$ & $\begin{array}{l}\text { Chloroform extract } \\
\text { (Stained sperms) }\end{array}$ & $\begin{array}{l}\text { Pet ether extract } \\
\text { (Stained sperms) }\end{array}$ \\
\hline Control & 100 & 100 & 100 & 100 \\
\hline $100(\mu \mathrm{g} / \mathrm{ml})$ & 92 & 95 & 95 & 96 \\
\hline $200(\mu \mathrm{g} / \mathrm{ml})$ & 88 & 85 & 92 & 87 \\
\hline $300(\mu \mathrm{g} / \mathrm{ml})$ & 64 & 72 & 87 & 83 \\
\hline $400(\mu \mathrm{g} / \mathrm{ml})$ & 53 & 61 & 81 & 78 \\
\hline $500(\mu \mathrm{g} / \mathrm{ml})$ & 41 & 49 & 76 & 72 \\
\hline $600(\mu \mathrm{g} / \mathrm{ml})$ & 32 & 37 & 71 & 68 \\
\hline $700(\mu \mathrm{g} / \mathrm{ml})$ & 18 & 22 & 65 & 63 \\
\hline $800(\mu \mathrm{g} / \mathrm{ml})$ & 8 & 13 & 59 & 58 \\
\hline $900(\mu \mathrm{g} / \mathrm{ml})$ & 0 & 5 & 53 & 55 \\
\hline $1000(\mu \mathrm{g} / \mathrm{ml})$ & 0 & 0 & 48 & 51 \\
\hline
\end{tabular}

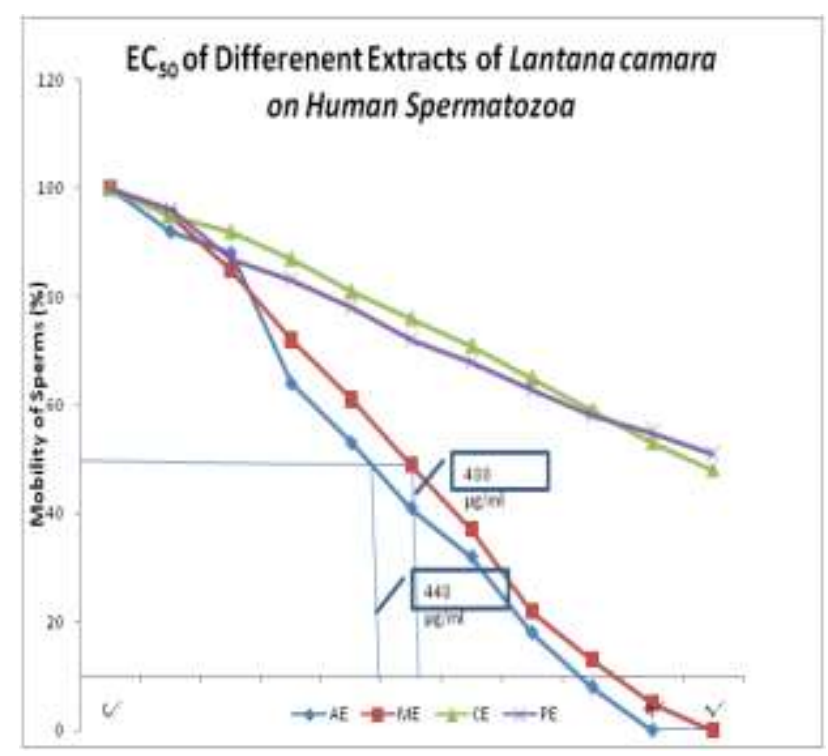

Figure 1: EC50 of various Extracts on Human Spermatozoa. EC50 of Aqueous extract and Methanolic extract was found to be $448 \mu \mathrm{g} / \mathrm{ml}$ and 480 $\mu \mathrm{g} / \mathrm{ml}$ respectively.

\section{Preliminary Phyto-chemical screening of Plant Extracts}

\section{Detection of alkaloids}

Hager's and Wagner's test showed positive results in case of chloroform extract and negative results in case of all other extracts.

\section{Detection of tannins}

Methanolic extract and aqueous extract showed positive results for tannins. Negative results were obtained in case of all other extracts.

\section{Detection of flavonoids}

Methanolic extract and aqueous extract showed positive results for flavonoids. Negative results were obtained in case of all other extracts.

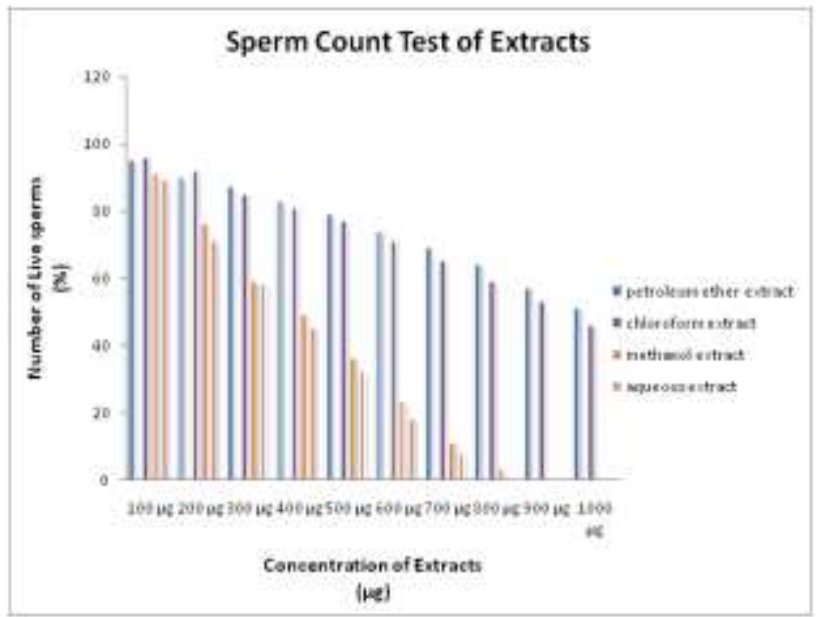

Figure 2: Sperm count test for various extracts treated semen samples.

\section{Detection of saponins}

Methanolic extract, petroleum ether extract and aqueous extract showed positive results for saponins. Negative results were obtained in case of chloroform extract.

\section{Detection of steriods}

Petroleum ether extract and aqueous extract showed positive results for steriods. Negative results were obtained in case of other extracts. 


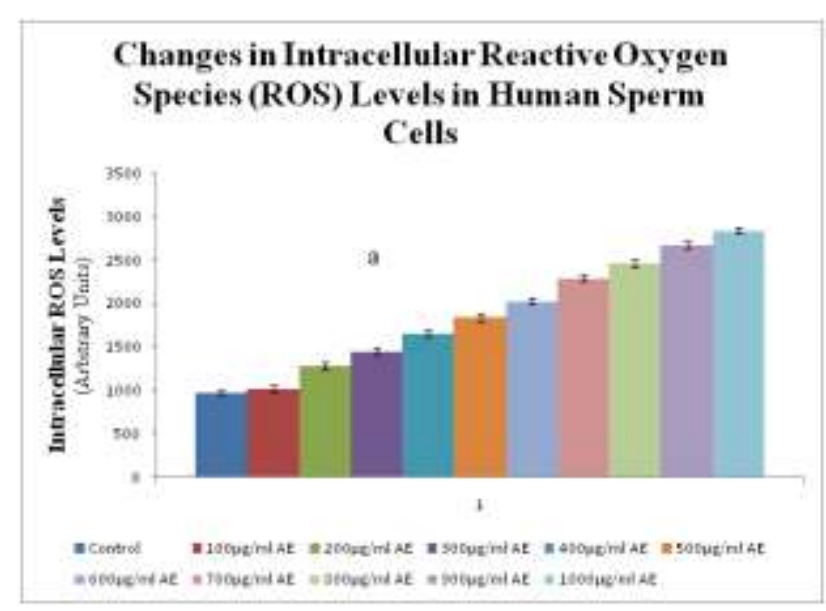

Figure 3: Changes in intracellular Reactive Oxygen Species (ROS) level of human sperm after treatment with different concentrations of Aqueous extract of Lantana camara in vitro. FeSO4 $(100 \mathrm{mM})$ was used as positive control. Values are Mean \pm SEM of three independent experiments. Significance of difference from control is denoted as: 0.001 .

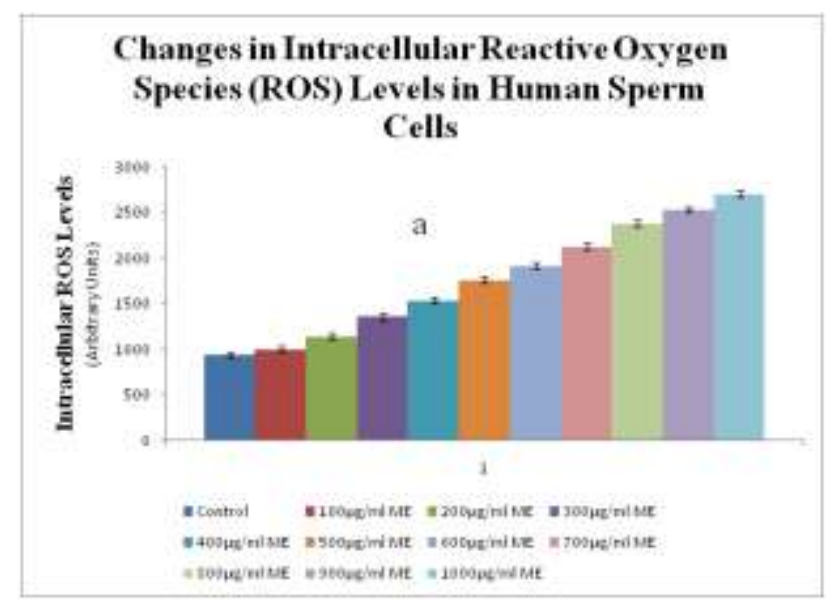

Figure 4: Changes in intracellular Reactive Oxygen Species (ROS) level of human sperm after treatment with different concentrations of Methanolic extract of Lantana camara in vitro. FeSO4 $(100 \mathrm{mM})$ was used as positive control. Values are Mean \pm SEM of three independent experiments. Significance of difference from control is denoted as: 0.001 .

\section{Detection of proteins}

Petroleum ether extract and methanol extract showed positive results for proteins. Negative results were obtained in case of other extracts.

\section{Detection of anthraquinone glycosides}

Petroleum ether extract showed positive results for anthraquinone glycosides. Negative results were obtained in case of other extracts.
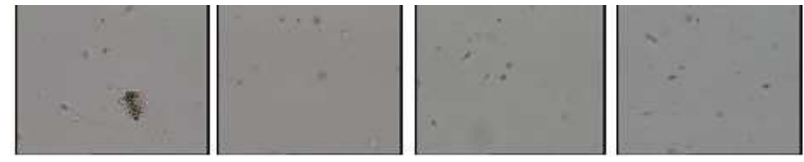

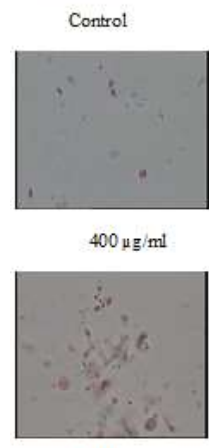

$800 \mu \mathrm{g} / \mathrm{ml}$

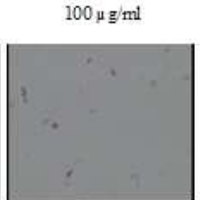

$500 \mu \mathrm{g} / \mathrm{ml}$

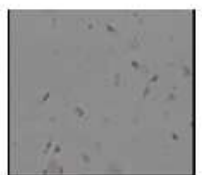

$900 \mu \mathrm{g} / \mathrm{ml}$

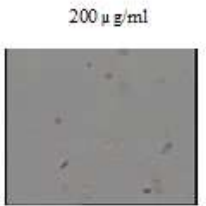

$600 \mu \mathrm{g} / \mathrm{ml}$

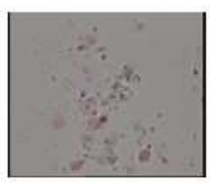

$1000 \mu \mathrm{g} / \mathrm{ml}$

Figure 5: Photographic representation of sperm viability test after treatment with different concentrations aqueous extract.
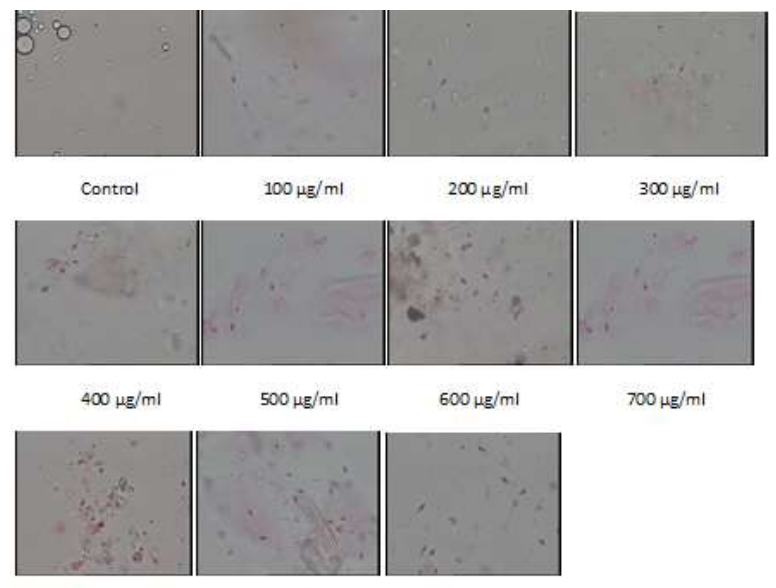

$800 \mu \mathrm{g} / \mathrm{ml} \quad 900 \mu \mathrm{g} / \mathrm{ml} \quad 1000 \mu \mathrm{g} / \mathrm{ml}$

Figure 6: Photographic representation of sperm viability test after treatment with different concentrations methanolic extract.

\section{Sperm mobility and $\mathrm{EC}_{50}$}

In the present protocol, control group showed high rate of mobility (94-100\%), which was kept as standard for comparison with test groups. There was a progressive decrease in sperm mobility after treatment with various concentrations of different extracts (Table 2). At concentration $600 \mu \mathrm{g} / \mathrm{ml}$ of aqueous extract, sperms were immobilized within 40 seconds and at $700 \mu \mathrm{g} / \mathrm{ml}$ concentration of methanolic extract, $92 \%$ reduction in mobility was noted within 20 seconds. With aqueous extract, at concentration $200 \mu \mathrm{g} / \mathrm{ml}$ slight reduction in mobility was observed but at $400 \mu \mathrm{g} / \mathrm{ml}$ concentration, significant decline in mobility was noted within 20 seconds. Moreover sperm mobility was reduced to 
approximately $93 \%$ within 20 seconds at a concentration $600 \mu \mathrm{g} / \mathrm{ml}$. In case of methanolic extract, it was observed that treatment with methanolic extract at $400 \mu \mathrm{g} / \mathrm{ml}$ concentration, resulted in $75 \%$ decrease in the mobility within 15 seconds and more significant reduction of sperms mobility and motility was observed i.e. approximate $95 \%$ decline in mobility at concentration $700 \mu \mathrm{g} / \mathrm{ml}$ within 10 seconds. It was interesting to note that petroleum ether and chloroform showed sperm immobility effect only at very high concentration. Nearly $95 \%$ of immobility of sperms was observed at $500(\mu \mathrm{g} / \mathrm{ml})$ concentrations of aqueous extract. About $92 \%$ reduction in mobility was noted at $600(\mu \mathrm{g} / \mathrm{ml})$ concentration of methanolic extract.
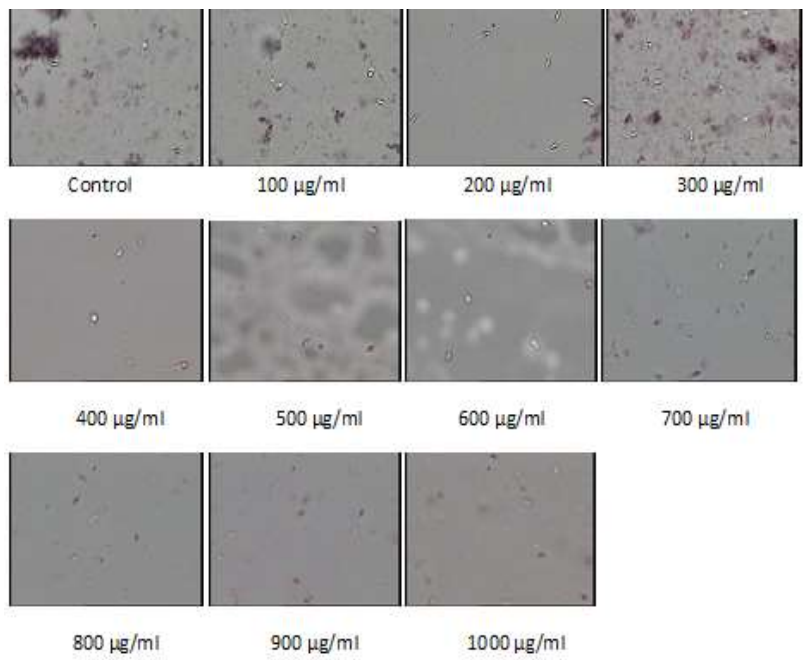

Figure 7: Photographic representation of sperm viability test after treatment with different concentrations chloroform extract.
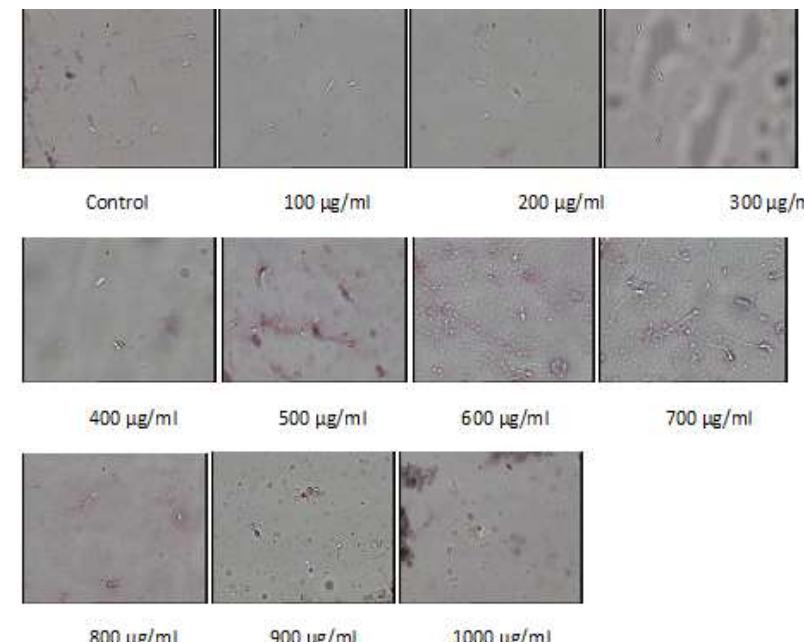

Figure 8: Photographic representation of sperm viability test after treatment with different concentrations petroleum ether extract.

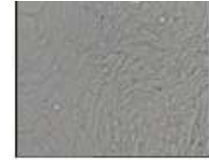

Control

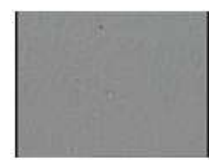

$400 \mu \mathrm{g} / \mathrm{ml}$

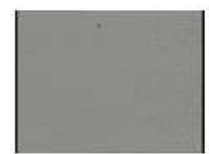

$800 \mu \mathrm{g} / \mathrm{ml}$

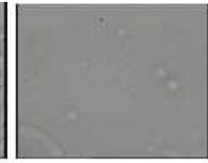

$100 \mu \mathrm{g} / \mathrm{ml}$

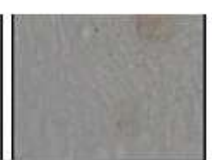

$500 \mu \mathrm{g} / \mathrm{ml}$

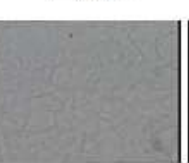

$900 \mu \mathrm{g} / \mathrm{ml}$

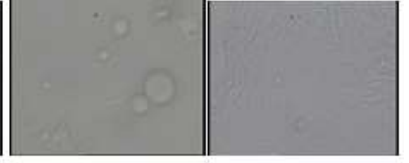

$200 \mu \mathrm{g} / \mathrm{ml}$

$300 \mu \mathrm{g} / \mathrm{ml}$

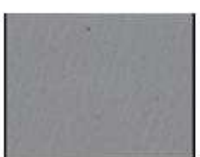

$600 \mu \mathrm{g} / \mathrm{ml}$

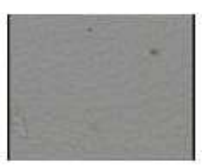

$700 \mu \mathrm{g} / \mathrm{ml}$
Figure 9: Photographic representation of acrosomal status and function of sperm after treatment with different concentrations of aqueous extract.

Significant reduction in number of holes was observed at different concentrations of extract.
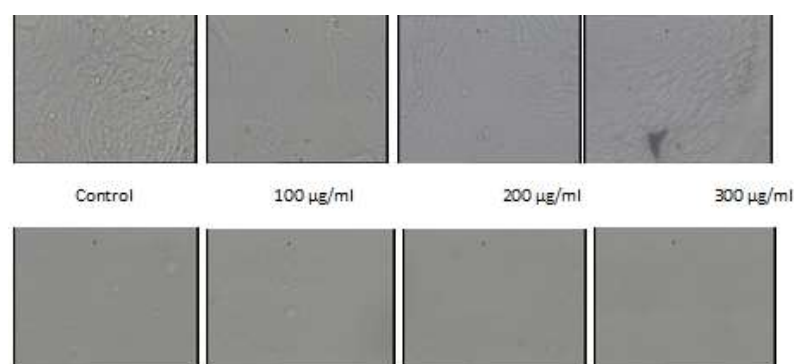

$200 \mu \mathrm{g} / \mathrm{ml}$

$300 \mu \mathrm{g} / \mathrm{ml}$

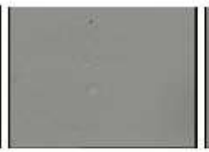

$500 \mu \mathrm{g} / \mathrm{ml}$

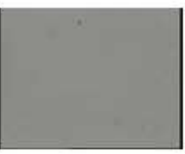

$600 \mu \mathrm{g} / \mathrm{ml}$

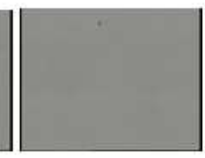

$400 \mu \mathrm{g} / \mathrm{ml}$

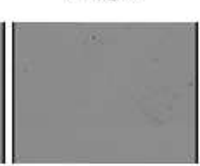

$900 \mu \mathrm{g} / \mathrm{m}$

$1000 \mu \mathrm{g} / \mathrm{ml}$

Figure 10: Photographic representation of acrosomal status and function of sperm after treatment with different concentrations of methanolic extract.

Significant reduction in number of holes was observed at different concentrations of extract.

From the above results, $\mathrm{EC}_{50}$ of various extracts (the concentration which resulted in decrease/cessation in the mobility in $50 \%$ of sperm cells under observation) was noted. $\mathrm{EC}_{50}$ of petroleum ether extract, chloroform extract, methanolic extract and aqueous extract was $900 \mu \mathrm{g} / \mathrm{ml}, \quad 1000 \mu \mathrm{g} / \mathrm{ml}, \quad 480 \mu \mathrm{g} / \mathrm{ml}$ and $448 \mu \mathrm{g} / \mathrm{ml}$ respectively (Figure 1).

\section{Sperm viability test}

Control group showed approximately $98 \%$ viability for 1 hour, which was as standard to compare with test groups (Table 3). Viability of sperm in the aqueous extract treated group at a concentration $200 \mu \mathrm{g} / \mathrm{ml}$ was found to 
be significantly reduced (within 30secs) compared to the control. The number of stained sperm cell further increased with time, and all the sperm were found nonviable after $1 \mathrm{~min}$ of contact with increased concentration of extract, the number of non-viable sperm cells increased progressively (Figure 5). Similarly treatment of sperm suspension with methanolic extract at concentration $300 \mu \mathrm{g} / \mathrm{ml} / \mathrm{ml}$, resulted in significant increase in the number of stained sperm cells as compared to the control within 25 secs. The number of stained sperms cells significantly increased with subsequent increase in concentration of extract (Figure 6). Furthermore, with aqueous and methanolic extract, significant decrease in the number of viable sperm cells and increase in the number of stained (non-viable) sperm cells were observed at minimum concentration i.e. $480 \mu \mathrm{g} / \mathrm{ml}$. This fall in number of viable sperms were noted within $10 \mathrm{secs}$. No significant increase in the no. of non-viable cells was observed after treatment with petroleum ether and chloroform extract (Figure 7 and Figure 8). Significant decrease in the number of viable sperm cells was observed at on increasing the concentrations extracts.

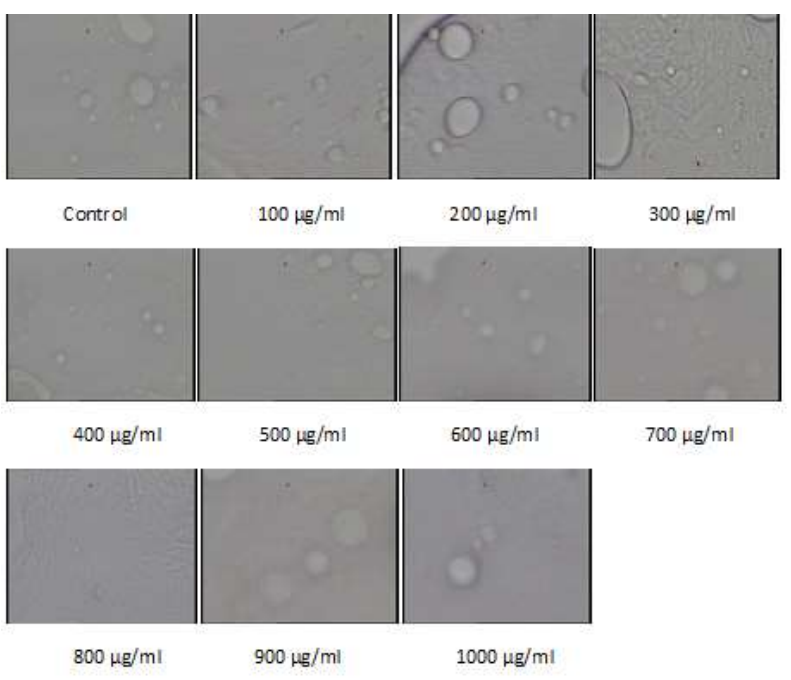

Figure 11: Photographic representation of acrosomal status and function of sperm after treatment with different concentrations of chloroform extract.

Significant reduction in number of holes was observed at different concentrations of extract.

\section{Hypo-osmotic Swelling Test}

Control group sperms were showed $96 \%$ of tail curling movement. On treatment of semen suspension with low concentrations (up to $100 \mu \mathrm{g} / \mathrm{ml}$ ) of aqueous extract of the drug, there was no significant change in the tail curling movement. However, at high concentrations i.e. $300 \mu \mathrm{g} / \mathrm{ml}$, the aqueous extract treatment resulted in a reduction in tail curling up to $45 \%$ within 30 secs. At concentration $(500 \mu \mathrm{g} / \mathrm{ml})$, highly significant reduction (up to $85 \%$ ) in tail curling was noted within 30 secs. At concentration of $200 \mu \mathrm{g} / \mathrm{ml}$ of methanol extract, about
$10 \%$ reduction in tail curling of sperms was observed within 30 seconds. The percentage of tail curling decreased significantly $(85 \%)$ within 25 secs with a subsequent increase in drug concentration to $600 \mu \mathrm{g} / \mathrm{ml}$ concentration of methanol extract. Furthermore, with ethanolic extract, $25 \%$ reduction in tail curling was observed within $15 \mathrm{secs}$ at concentration of $100 \mu \mathrm{g} / \mathrm{ml}$. The percentage of tail curling decreased significantly up to $90 \%$ within 10 secs with a subsequent increase in drug concentration to $700 \mu \mathrm{g} / \mathrm{ml}$ concentration of chloroform extract. Significant reduction in tail curling movement was observed on treatment with different extracts (Table 4).

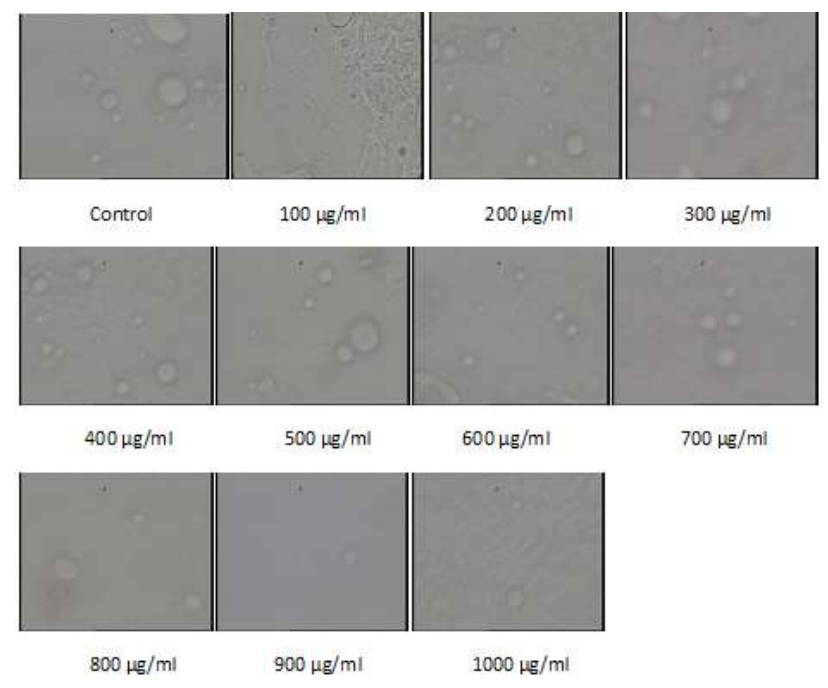

Figure 12: Photographic representation of acrosomal status and function of sperm after treatment with different concentrations of petroleum ether extract. Significant reduction in number of holes was observed at different concentrations of extract.

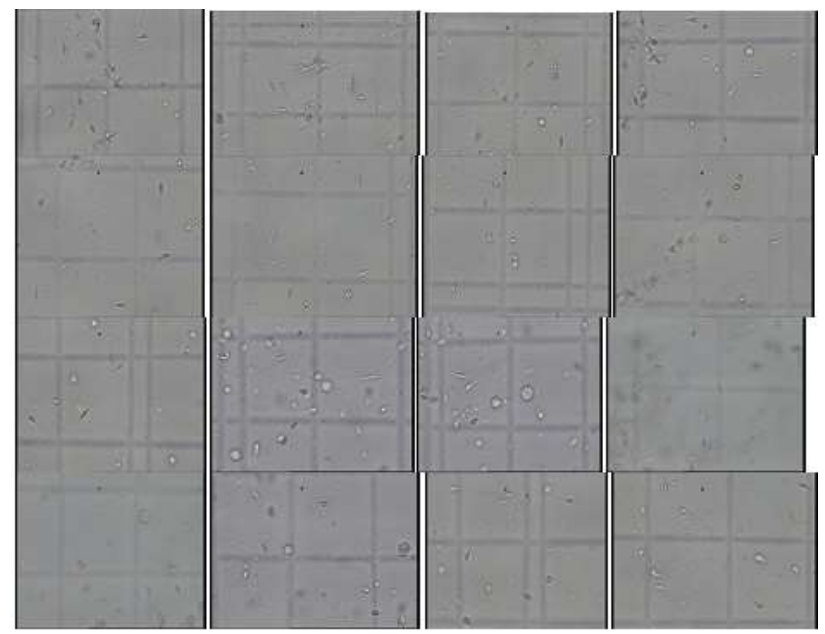

Figure 13: Photographic representation of sperm count after treatment with $400 \mu \mathrm{g} / \mathrm{ml}$ concentration of aqueous extract. Significant reduction in number of live sperm was observed on treated with different concentrations of extract. 


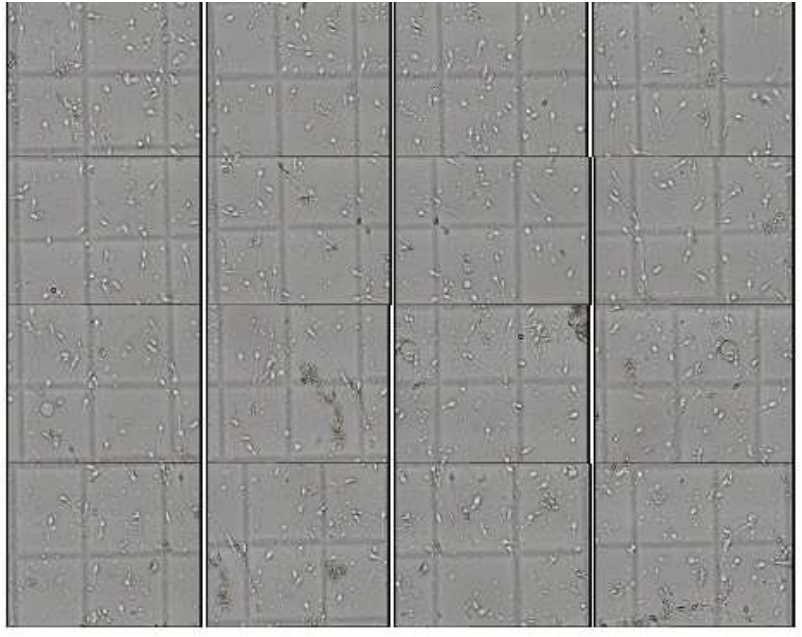

Figure 14: Photographic representation of sperm count after treatment with $500 \mu \mathrm{g} / \mathrm{ml}$ concentration of methanolic extract. Significant reduction in number of live sperm was observed on treated with different concentrations of extract.

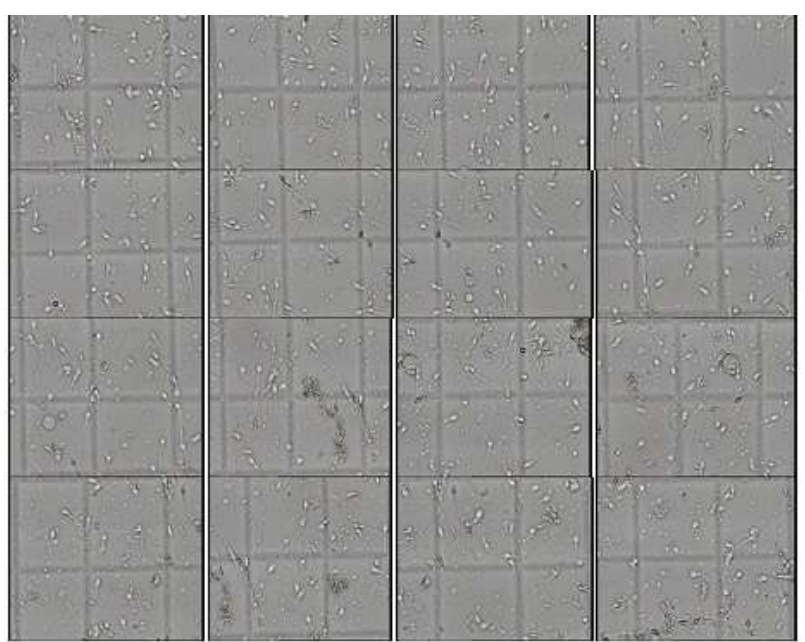

Figure 15: Photographic representation of sperm count after treatment with $900 \mu \mathrm{g} / \mathrm{ml}$ concentration of methanolic extract. Significant reduction in number of live sperm was observed on treated with high concentrations of extract.

\section{Acrosomal status and functional test}

In Acrosomal status and function test, highest number of holes on the gelatin coated glass slide was observed in case of control sample, which was taken as $100 \%$ (Table $5)$. By pretreatment with aqueous extract at concentration $100 \mu \mathrm{g} / \mathrm{ml}$, no significant changes were observed in number of holes on gelatin slides. However, at extract concentration $200 \mu \mathrm{g} / \mathrm{ml}$ significant reduction (28\%) was observed in number of holes on gelatin coated glass slide. Furthermore, at higher concentration $500 \mu \mathrm{g} / \mathrm{ml} 70 \%$ reduction in number of holes on gelatin coated glass slides was observed (Figure 9). In case of methanolic extract, at concentration of $100 \mu \mathrm{g} / \mathrm{ml}$, about $18 \%$ decline in number of holes on gelatin coated glass slides was observed. However, at extract concentration $300 \mu \mathrm{g} / \mathrm{ml}$, significant reduction $(40 \%)$ was observed in number of holes on gelatin coated glass slide. Furthermore, at higher $600 \mu \mathrm{g} / \mathrm{ml}$, significant reduction in number of holes $(76 \%)$ on gelatin coated glass slides was observed (Figure 10). In case of chloroform extract, at concentration of 100 $\mu \mathrm{g} / \mathrm{ml}$, nearly $5 \%$ reduction in number of holes on gelatin coated glass slides was observed (Figure 11). Furthermore, at concentration $600 \mu \mathrm{g} / \mathrm{ml}$, number of holes on gelatin coated glass slide was gradually decline to $33 \%$. However, at higher concentration $800 \mu \mathrm{g} / \mathrm{ml}$, significant reduction in number of holes $(53 \%)$ on gelatin coated glass slides was observed. In case of petroleum ether extract no significant reduction of holes on the gelatin coated glass slides was observed (Figure 12). At the concentration $1000 \mu \mathrm{g} / \mathrm{ml}$, only $33 \%$ reduction in the number of holes on gelatin coated glass slides. Reduction in number of holes was observed on gelatin coated slides on treatment with different extracts at different concentrations.

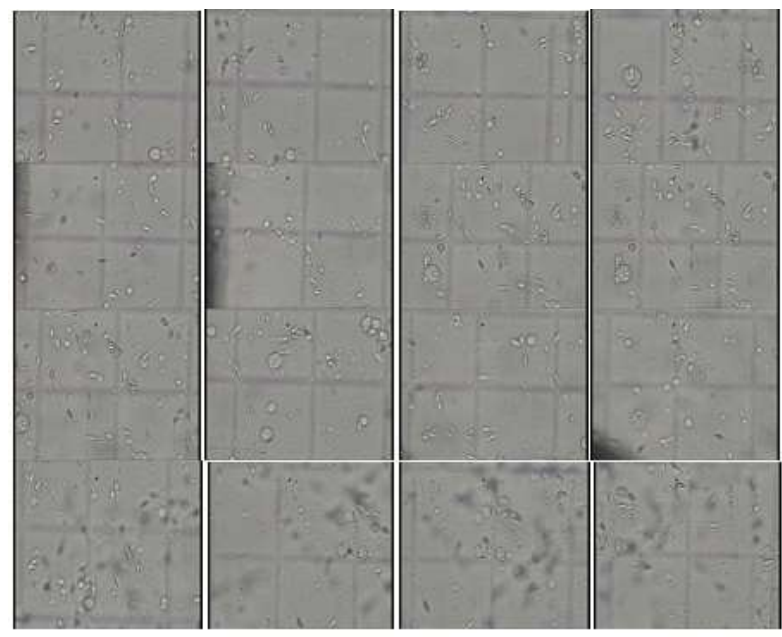

Figure 16: Photographic representation of sperm count after treatment with $1000 \mu \mathrm{g} / \mathrm{ml}$ concentration of methanolic extract. Significant reduction in number of live sperm was observed on treated with high concentrations of extract.

\section{Sperm count (Number of live or dead sperms)}

For evaluation of effect of extracts on sperm count, the sperm count of control group was taken $100 \%$ which was used to compare with different test concentrations (Table 6). At concentration of $100 \mu \mathrm{g} / \mathrm{ml}$ of aqueous extract, non-significant reduction in number of live sperms was observed within $1 \mathrm{~min}$ i.e. mortality rate of sperms was very low or negligible. However, at concentration 300 $\mu \mathrm{g} / \mathrm{ml}$, nearly $50 \%$ reduction in live sperms was observed within $40 \mathrm{secs}$. At concentration $500 \mu \mathrm{g} / \mathrm{ml}$, significant increase in mortality $(78 \%)$ of sperms was observed within 40 seconds (Figure 13). In case of methanol extract, at concentration $200 \mu \mathrm{g} / \mathrm{ml}$, nearly $37 \%$ mortality 
of sperms was noted within 30secs. At concentration 400 $\mu \mathrm{g} / \mathrm{ml} / \mathrm{ml}$ of extract, significant increase in mortality $(56 \%)$ of sperms within 30secs was observed. Furthermore, at higher concentration $600 \mu \mathrm{g} / \mathrm{ml}$ of extract, gradual increased in mortality $(78 \%)$ of sperms within 30secs was observed (Figure 14). In case of chloroform extract, at concentration $100 \mu \mathrm{g} / \mathrm{ml}$, nearly $5 \%$ reduction in number of sperms was observed. Furthermore, at concentration of $800 \mu \mathrm{g} / \mathrm{ml}$ of extract, significant increased mortality $(54 \%)$ of sperms was observed within 15 secs (Figure 15). In case of petroleum ether extract no significant sperm cell mortality was observed. At the concentration $100 \mu \mathrm{g} / \mathrm{ml}$, only $04 \%$ sperm cell mortality was observed. At the concentration $500 \mu \mathrm{g} / \mathrm{ml}$, only $28 \%$ sperm cell mortality was seen (Figure 16). Change in the number of live sperms significantly on increasing the concentration of different extracts (Table 6).

\section{In-vitro evaluation of ROS generation in human sperm}

ROS were induced in human sperm by the action of both aqueous extract and methanolic extract of Lantana camara. Much more significant ROS generation was seen with the use both extracts. Though ROS levels induced by Extracts were much lower as compared with $\mathrm{FeSO}_{4}$ (positive control), still the change was statistically significant in case of all the extracts (Figure 3 and Figure $4)$.

\section{DISCUSSION}

In the present study, contraceptive efficacy of various extracts of leaves of the plant Lantana camara were evaluated by a series of in-vitro experiments. The results of the present study reveal that the aqueous extract and methanolic extract of the leaves possess potent dose dependant sperm immobilizing effect. The immobilized or non-motile sperm cell is considered to be dead or noneffective. Therefore, in the sperm count analysis, after treatment with the plant extracts at various concentrations, there was a progressive decrease in the number of viable cells. Moreover chloroform and petroleum ether extractive also showed some sperm immobilizing effect at higher doses. The EC50 of various extracts was also noted.

The EC50 of petroleum ether extract, chloroform extract and ethanolic extract was $1000 \mu \mathrm{g} / \mathrm{ml}, 900 \mu \mathrm{g} / \mathrm{ml}, 400$ $\mu \mathrm{g} / \mathrm{ml}$ and $300 \mu \mathrm{g} / \mathrm{ml}$ respectively. Besides mobility and motility, several other parameters are also considered to be important in successful fertilization. Other factors such as sperm viability, hypoosmotic swelling test are also considered to be important and were therefore evaluated in the present study. ${ }^{18,19}$ Eosin-Nigrosin staining of the extract treated semen suspension also revealed a significant increase in the number of immotile/dead sperm cell. This result reveals that the phytoconstituents present in the extracts under consideration may interact with the sperm cell membrane components and thus may interfere with sperm cell membrane integrity. However further studies involving Scanning Electron Microscopy (SEM) is required to delineate the specific protein interaction involved in action of the plant drug.

In hypo-osmotic swelling test, the methanolic extract and aqueous extract of the leaves inhibited the tail curling movement of sperm cells at concentration of $380 \mu \mathrm{g} / \mathrm{ml}$ and $400 \mu \mathrm{g} / \mathrm{ml}$ respectively. Moreover, petroleum ether extract and chloroform extract also inhibited the tail curling movement of sperm cells at very higher concentrations $(1000 \mu \mathrm{g} / \mathrm{ml})$. These results indicate the potent sperm immobilizing property of Aqueous and methanolic extracts. Further investigations involved screened fractions of methanolic and aqueous extracts using column chromatography.

Our hypothesis regarding involvement of sperm cell membrane integrity alteration by the phytoconstituents of the extracts was further strengthened by evaluation of acrosome status and function test. It has been well documented the certain plant derivatives drastically inhibit sperm cell membrane associated enzymes like hyaluronidase and acrosin which are considered to be essential for the forward movement of the sperm cell in the cervix to execute the process of fertilization. ${ }^{20,21}$ The control group had maximum number of live and motile sperm cells which resulted in presence of large number of holes on the gelatin coated glass slide. The progressive decrease in the number of holes on the gelatin coated glass slides with a progressive increase in the concentration of various extracts further potentiates our hypothesis regarding involvement of cell membrane components in the observed sperm immobilizing effect of the extracts.

In various previous studies, a large numbers of plant derived secondary metabolites such as terpenes, flavonoids, sesquiterpens and phenols ${ }^{22}$ showed spermicidal properties. The monoterpine saponins isolated from Cyclomen parsicum, Primula vulgaris, Gypsophyla paniculata and Ruta graveolens have been reported to cause instant immobilization within 20 seconds of human spermatozoa. ${ }^{23,24}$ Various other terpenoid and phenolic acid rich plant extracts, like aqueous extracts of seeds of Echeveria gibbiflor, Chenopodium album, Cestrum parqu, Azadirachta indica, Carica papaya and leaf extracts of Achyranthes aspera have been shown to possess spermicidal properties. $^{25-29}$ The antifertility effects of Satureja khuzestanica essential oil on rat was also reported. ${ }^{30}$

However in the present investigation, phytochemical investigation of various extracts did not reveal any contributory evidences other than indicating the presence of saponins and tannins.

Oxidative stress (OS) arises when excess free radicals overwhelm the antioxidant defence of the male reproductive tract, damaging cells, tissues and organs. ${ }^{31-33}$ 
Seminal OS correlates negatively with sperm concentration, motility and function-adversely affecting fusion events required for fertilization. ${ }^{34-36}$ The polyunsaturated fatty acids of the sperm plasma membrane are susceptible to ROS damage as low concentrations of the scavenging enzymes are found in sperm cytoplasm. ${ }^{37}$ ROS attack on the cell membrane leads to a chain of chemical reactions called lipid peroxidation, which reduces membrane fluidity and the activity of membrane enzymes and ion channels, resulting in the inhibition of normal cellular mechanisms required for fertilisation. End products of lipid peroxidation, such as malondialdehyde, are measured to estimate the extent of peroxidative damage. Deoxyribonucleic acid bases and phosphodiester backbones of DNA can also experience peroxidative damage. Oxygen-radical induced caspase and endonuclease mechanistic pathways have been proposed as a potential cause of double-stranded DNA damage. ${ }^{38}$ Patients with high-seminal fluid OS were found to have sperm with multiple single and double DNA strand breaks. ${ }^{39}$ Spermatozoal DNA is usually protected by its compact organisation and by antioxidants in the seminal plasma. Spermatozoa themselves are incapable of DNA repair and must depend on the oocyte for repair after fertilisation; however, knowledge concerning the process remains limited. ${ }^{40}$ ROS exposure may result in DNA base modification, production of base-free sites, deletions, frame shifts, DNA crosslinks and chromosomal aberrations. $^{41,42}$ A 8-hydroxy-2-deoxyguanosine (8$\mathrm{OHdG})$ is a biomarker that may determine the extent of ROS-induced DNA damage. ROS may promote apoptosis: a process in which the body removes old and senescent cells, leading to decreased sperm concentration. ${ }^{43}$ In a study from a well-established centre, levels of caspases, proteases involved in apoptosis, correlated with ROS levels- implicating OS in increased apoptosis in mature spermatozoa. ${ }^{44}$ The results showed that apoptosis could be induced in cell cultures with $\mathrm{H}_{2} \mathrm{O}_{2}$, further implicating ROS in the induction of apoptosis. We conclude by a postulation that pro-oxidant nature of lantana camara as is evidenced by a dose dependant decrease in the DPPH scavenging capacity of ascorbic acid in the presence various Lantana camara extracts.

However further studies are required to delineate the molecular mechanisms involved in the observed effect and the quantitatively estimate the level of different ROS species in extract treated semen samples.

\section{ACKNOWLEDGEMENTS}

The authors are highly thankful to Prof. (Dr.) P.K Ahuja, Head, Department of Botany, Khalsa College, Amritsar, Punjab, India for their help in identification and authentication of the plant material.
Funding: No funding sources

Conflict of interest: None declared

Ethical approval: The study was approved by the Institutional Ethics Committee [KCP/IAEC/2015/03]

\section{REFERENCES}

1. Herfindal ET and Gourley DR. In: Text Book of Therapeutics, Drug and Disease Management; Ed. $7^{\text {th }}$; Philadelphia, Lippincott Williams and Wilkins; 2000: 2019-2025.

2. Alvarez-Gomez AM, Cardona-Maya W, Forero J, Cadavid AP. Human Spermicidal Activity of Passiflora edulis Extract. J. Rep. Contra., 2010; 21(2): 95-100.

3. Chakraborti K, Pal S, Bhattacharya AK. Sperm immobilization activity of Allium sativum $\mathrm{L}$ and other plant extracts. Asian J Androl. 2003; 5:131-5.

4. Kamal R, Gupta RS, Loyiya NK. Plants for male fertility regulation. Phytotherap Res. 2003;17:159-590.

5. Gupta, R.S, Sharma, R. A review on medicinal plants exhibiting antifertility activity in males. Natur. Prod. Rad. 2006;5(5):389-410.

6. Badakhshan MP, Sasidharan S, Rameshwar NJ, Ramanathan S. Comparative study: Antimicrobial activity of methanol extracts of Lantana camara Various Parts. Phcog. Res. 2009;1(6):348-51.

7. Srivastava MC, Kant V, Tewari JP. Anti-inflammatory activity of roots of Argyreia speciosa (Samundrashokha). Mediscope. 1972;15:219-22.

8. Srivastava, P, Kasoju, N, Bora, U, Chaturvedi, R. Accumulation of Betulinic, Oleanolic, and Ursolic acids in in vitro cell cultures of Lantana camara $\mathrm{L}$. and their significant cytotoxic effects on $\mathrm{HeLa}$ cell lines. Biotechnol. Bioprocess Eng. 2010;15(6):1038-46.

9. Srivastava, P, Kasoju, N, Bora, U, Chaturvedi, R. Dedifferentiation of leaf explants and cytotoxic activity of an aqueous extract of cell cultures of Lantana camara L. Plant Cell Tissue Organ Cult. 2009;99(1):17.

10. Sharma OP, Vaid J, Pattabhi V, Bhutani KK. Biological action of lantadene $\mathrm{C}$, a new hepatotoxicant from Lantana camara var. aculeata. J Biochem Toxicol. 1992;7 (2):73-9.

11. Henkel RR. Leukocytes and oxidative stress: dilemma for sperm function and male fertility. Asian J Androl. $2011 ; 13$.

12. Srivastava, P, Chaturvedi, R. Simultaneous determination and quantification of three pentacyclic triterpenoids-betulinic acid, oleanolic acid, and ursolic acid-in cell cultures of Lantana camara L. In Vitro Cell Dev Biol Plant. 2010;46 (6):549-57.

13. Sander FV, Cramer SD. A practical method of testing the spermicidal action of chemical contraceptives. Hum Fertil. 1941;6:134-8.

14. World Health Organization. In: Laboratory manual for the examination of human Semen; $5^{\text {th }}$ ed. 2010; pp. 3244.

15. Gopal Krishnan K. Standardized procedures in human semen analysis. Curr Sci. 1995;68:353-62.

16. World Health Organization. In: Laboratory manual for the examination of human semen and sperm-cervical mucus interaction; Ed. 4th, New York: Cambridge University. 1999; pp. 68-70. 
17. Wang, H, Joseph JA. Quantifying cellular oxidative stress by dichlorofluorescein assay using microplate reader. Free Radic Bio Med. 1999;27:612-6.

18. WHO. In: Nutrition for health and development and A global agenda for combating malnutrition, World Health Organization, Nutrition for Health and Development (NHD), Sustainable Development and Healthy Environments (SDE). 2000.

19. Jayendran RS, Van der Ven HH, Perez-Pelaez M, Crabo BG, Zaneveld LJD. Development of an assay to assess the functional integrity of the human sperm membrane and its relationship to other semen characteristics. J Reprod Fertil. 1984;70:219-28.

20. Lohiya NK, Kothari LK, Manivannan B, Mishra PK, Pathak N. Human sperm immobilization effect of Carica papaya seed extracts: as in vitro Study. Asian J Androl. 2000; 2:103-9.

21. Pimentel D. World Overpopulation. Environ Dev Sustain. 2012;14:151-2.

22. Farns Worth NR, Waller DP. Current status of plant products reported to inhibit sperm. In Res front fertile regul. 1984;2:1-16.

23. Primorac M. In vitro determination of the spermicidal activity of plant Saponins. Pharmazie. 1985;40:585.

24. Harat ZN. Immobilization effect of Ruta graveolens L. on human sperm: a new hope of male contraception. J Ethnopharmacol. 2008; 115:36-41.

25. Delgado NM. Effects of a purified fraction from Echeveria gibbiflora aqueous crude extract on guineapig spermatozoa. Phytother Res. 1999;13:46-9.

26. Kumar S, Biswas S, Mandal D, Roy HN, Chakraborty S, Kabir SN, et al. Chenopodium album seed extract:a potent spermimmobilization agent both in vitro and in vivo. Contraception. 2007;75:71-8.

27. Souad K, Ali S, Mounir TM. Spermicidal activity of extract from Cestrum parqui. Contraception. 2007;75:152-6.

28. Khillare B, Shrivastav TG. Spermicidal activity of Azarichta indica (neem) leaf extract. Contraception. 2003;68:225-9.

29. Paul D, Bera S, Jana D, Maiti R, Ghosh D. In vitro determination of the contraceptive spermicidal activity of a composite extract of Achyranthes aspera and Stephania hernandifolia on human semen. Contraception. 2006;73:284-8.

30. Haeri S, Minaie B, Amin G, Nikfar S, Khorasani R, Esmaily H. Effect of Satureja Khuzestanica essential oil on male rat fertility. Contraception. 2006;77: 495-9.
31. Agarwal A, Deepinder F, Sharma RK, Ranga G. Effect of cell phone usage on semen analysis in men attending infertility clinic: an observational study. Fertil Steril. 2008;89:124-8.

32. Kemal Duru N, Morshedi M, Oehninger S. Effects of hydrogen peroxide on DNA and plasma membrane integrity of human spermatozoa. Fertility and Sterility. Int J Mol Sci. 2000;13:14026-52.

33. Gomez, E, Irvine, D.S, Aitken, R.J. Evaluation of a spectrophotometric assay for the measurement of malondialdehyde and 4-hydroxyalkenals in human spermatozoa, relationships with semen quality and sperm function. Int J Andrology. 1998;21:81-94.

34. Aitken, R.J, Baker, M.A. Causes and consequences of apoptosis in spermatozoa; contributions to infertility and impacts on development. Int. J. Dev. Biol., 2013; 57: 265-272.

35. Sharma RK, Agarwal A. Role of reactive oxygen species in male infertility. Urology. 1996;48:835-50.

36. Sikka SC. Relative impact of oxidative stress on male reproductive function. Curr Med Chem. 2001;8:851-62.

37. Saleh RA, Agarwal A. Oxidative stress and male infertility: from research bench to clinical practice. J. Andro. 2002;23:737-52.

38. Sakkas D, Alvarez J. Sperm DNA fragmentation: mechanisms of origin, impact on reproductive outcome, and analysis. Fertility and Sterility. 2010;93:1027-36.

39. Twigg JP, Irvine DS, Aitken RJ. Oxidative damage to DNA in human spermatozoa does not preclude pronucleus formation at intracytoplasmic sperm injection. Hum Reprod. 1998;13:1864-71.

40. Aitken RJ, Baker MA, Sawyer D. Oxidative stress in the male germ line and its role in the aetiology of male infertility and genetic disease. Reproductive Biomedicine Online. 2003;7:65-70.

41. Duru N, Morshedi M, Oehninger S. Effects of hydrogen peroxide on DNA and plasma membrane integrity of human spermatozoa. Fertility and Sterility. 2000;74:1200-7.

42. Agarwal A, Said TM. Role of sperm chromatin abnormalities and DNA damage in male infertility. Hum. Reprod. Update. 2003;9:331-45.

43. Agarwal A, Saleh RA, Bedaiwy MA. Role of reactive oxygen species in the pathophysiology of human reproduction. Fertil Steril. 2003;79:829-43.

44. Wang X, Sharma RK, Sikka SC, Thomas AJ, Falcone $\mathrm{T}$, Agarwal A. Oxidative stress is associated with increased apoptosis leading to spermatozoa DNA damage. J Andro. 2003;23:737-52.

Cite this article as: Bhatia N, Singh $\mathrm{K}$, Shorey G, Singh G, Dhawan R. Evaluation of contact spermicidal potential of Lantana camara leaf extracts on human spermatozooa. Int J Reprod Contracept Obstet Gynecol 2016;5:3935-47. 